\title{
Simulated cattle fever tick infestations in rotational grazing systems
}

\author{
P.D. TEEL, W.E. GRANT, S.L. MARIN, AND J.W. STUTH
}

Authors are with the Department of Entomology, Department of Wildlife and Fisheries Sciences, Department of Rangeland Ecology and Management, Texas A\&M University, College Station, Tex. 77843-2126.

Abstract

Prior simulation analysis of cattle fever tick population dynamics has indicated that fixed rotation, short duration grazing (SDG) systems could mediate the spread of ticks among pastures if rest periods were greater than 100 to 150 days. A question arose whether variable rotations with rest periods approaching 35-70 days could mediate the spread of ticks within these rapid, rotational grazing systems. An 8-pasture:1-herd extensive (26-34 days:182-238 days graze:rest) and intensive (5-10 days: 35-70 days graze:rest) short duration grazing system was simulated over a 2-year period after a spring and fall introduction of infested animals using a model depicting both temporal and spatial processes involved in host-parasite-landscape interactions. The extensive SDG system was infested for 639 and 424 days for spring and fall introductions, respectively. The intensive SDG system was continuously infested throughout the 24 -month simulation. Although the intensive SDG system was continuously reinfested, there were more frequent tick-free periods in the fall introduction than the spring introduction. These sinulations indicate that rest periods exceeding 150 days are necessary to minimize the rate and extent of spread of ticks in variable rotational grazing systems. These considerations are pertinent to the goals of both control and eradication strategies.

Key Words: modeling, cattle fever ticks, short duration grazing

Grazing systems are generally applied to induce a desired suc cessional change and(or) to improve harvest efficiency to allow the land to support optimal numbers of animals in either the short-or long-term. While management generally focuses on vegetation change and animal production, grazing systems can have other ramifications relative to sustainability of the ranch firm. The introduction of ticks and tick-borne diseases is a major concern throughout tropical and subtropical grazing lands (McCosker 1981, Sonenshine 1993). It has long been established that grazing strategies can affect tick population dynamics and spread of tickborne diseases (Barnard 1991, Sutherst et al. 1979, Palmer et al.

\footnotetext{
The authors wish to thank Mr. Michael Corson for technical assistance, and the Grazing Animal Nutrition Laboratory personnel for Spanish language translation. This project was supported in part by the Research Enhancement Program of the Texas Agricultural Experiment Station, and by USDA Formula Animal Health project TEX08405.

Manuscript accepted 8 Mar. 1998.
}

Analisis previo de la dinamica poblacional de las garrapatas de la fiebre de las vacas, ha indicado que sistemas de pastoreo de ciclos de rotacion cortos (CRC) puede promover la dispersion de las garrapatas de un potrero a otro, no asi si los periodos de descanso son mas largos que 100 a 150 dias. Esto hizo surgir la pregunta si rotaciones con periodos de descanso abordando 35 a 70 dias podria promover la difusion de las garrapatas en estos tipos de sistemas de pastoreo.

1976, Waters 1972, Wharton et al. 1969, Tatchell 1992, Schmidtmann 1994). Increased importation of cattle from Mexico in 1995-96 and the broadening specter of acaricide resistance among cattle fever ticks, Boophilus annulatus and B. microplus, in that country (Fragoso ct al. 1995) has increased concerns regarding tick and tick-borne disease introductions in the Mexico-United States border region. Ecological processes mediating the spread of these ticks and risk of tick-borne diseases affect management strategies and regulatory program detection and eradication procedures are important to producers and agencies on both sides of the border.

Cattle fever ticks transmit hemoparasites (Babesia bigemina and $B$. bovis) that cause a fatal disease in immunologically susceptible cattle (McCosker 1981), known as bovine babesiosis. Babesia transmission occurs during bloodfeeding via the saliva of either larvae or nymphs, depending on the species combination of the hemoparasite and tick vector (Friedhoff and Smith 1981). The host range for these ticks is generally restricted to large ungulates, with a preference for cattle. Boophilus ticks complete their life cycle by alternating a bloodfeeding phase on a single host with an off-host phase completed at the soil:vegetation interface in which gravid females lay eggs and larvae are produced to ascend vegetation for attachment to the next host. Limited lateral movement by these ticks off the host mcans that dispersal and maintenance of Boophilus ticks are dependent upon the interactions and processes occurring between the hosts and landscape.

Recently, Teel et al. (1996) developed a simulation model for cattle fever tick population dynamics to evaluate ecological processes in cow-tick-landscape interactions. Their model integrated both temporal and spatial factors controlling host-parasitelandscape interactions. The initial thrust of the modeling work was to gain a better understanding of tick-habitat interactions. 
Tick populations in grasslands tended to be smaller and exhibited more abrupt peaks than those in mesquite and mixed brush canopied habitats. Cattle grazing these lower-structure habitats have a greater probability of detecting and avoiding clusters of tick larvae (Sutherst et al. 1986). Habitat type was the most sensitive variable in the model affecting population dynamics in a pasture. Teel et al. (1997) further explored temporal use of landscapes with different types of habitats, simulating an array of fixed, 8-pasture, 1-herd rotational grazing systems with 49-, 98-, 147-, 196-, and 245-day rest periods. Their data indicated that rest periods greater than 98 days significantly reduced reinfestation over a 2-year simulation on grasslands. Periods greater than 147 days were required to obtain the same response in mesquite (Prosopis glandulosa var. glandulosa L.) and mixed-brush dominated shrublands of South Texas.

Diversity of activities on ranches requires flexibility in rotation schedules, with the greatest modification occurring in coordination with working cycles for the livestock, reproductive/production cycles of the cattle and growth/quality patterns of the vegetation. Waters (1972) indicated that 120-day rests were optimum for tick control but 60-90-day rotations better fit ranch working cycles in central and northern Queensland coastal areas of Australia. Also, Heitschmidt and Taylor (1991) indicated that intensive short duration grazing systems need to adjust rotation schedules with changes in forage production cycles to optimize animal production. The issue arises whether more flexible application of grazing sequences with shorter grazing cycles could overcome higher infestation rates associated with shorter grazing cycles as noted by Teel et al. (1997). The present paper examines whether flexible grazing strategies responsive to differential forage growth rates mediate infestation rates of cattle fever ticks in simulated short duration grazing systems.

\section{Methods}

The study was conducted using a model of the cattle fever tick life cycle containing submodels for tick development on moderately tick-resistant Bos taurus-type cattle, tick survival in a mixed-brush off-host environment, and cow movement-tick acquisition (Fig. 1) (Teel et al. 1996). The model consists of 3 submodels representing (1) tick development on cattle from larvae to nymphs to adults, (2) off-host development and survivorship in pastures containing a mixed habitat of mixed-brush mottes and open grassland interspaces, and (3) movement of cattle among pastures. Tick larvae are acquired by cattle through encounter rate and pick-up rate variables. Tick mortality functions occur at appropriate points during the on-host and off-host

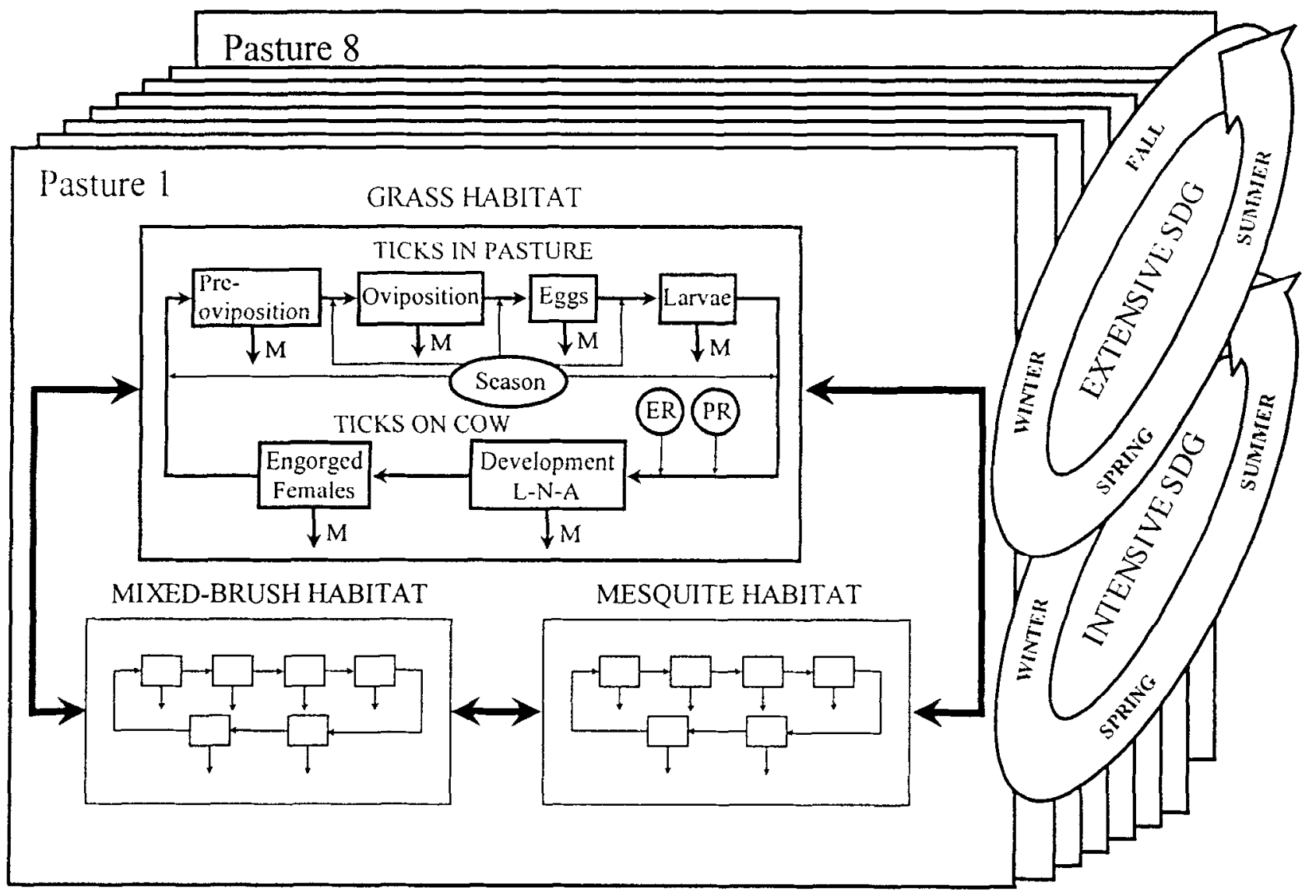

Fig. 1. Conceptualization of the cattle fever tick model. The model consists of 3 submodels representing (1) tick development on cattle (L-larval, N-nymphal, A-Adult), (2) off host development and survivorship in pastures containing a mixed habitat of mixed brush mottes and open grassland interspaces, and (3) movement of cattle among pastures. Tick larvae are acquired by cattle through encounter rate (ER) and pick-up rate (PR). Mortality functions (M) occur at indicated points. 
components. The influence of seasonal climate changes and habitat specific microclimate on egg production, incubation and larval survival during the off-host phase of the life cycle are based upon field and laboratory studies (Teel 1991, and Teel et al., unpub.) and reproduced through life tables in the model. The model was developed using STELLA II (Version 3.05, High Performance Systems, Inc, 1994) running on a MacIntosh Quadra 610 computer. The model runs on daily time-step and maintains separate identity for each daily cohort of ticks.

A series of 2-year simulations were conducted on 2 contrasting short- duration grazing (SDG) strategies. The extensive system employed an 8-pasture:1 herd regime with 26-34 days graze and 182-238 days rest (Table 1 ). These systems have been referred to as high intensity-low frequency rotational grazing (Heitschmidt and Taylor 1991). The intensive grazing system also used 8 pastures, but with a 5-10 days graze and 35-70 days rest sequence. A vegetation growth curve was derived from a panel of experts familiar with 16 major plant communities representative of the subtropical thornshrub region of South Texas and Northeastern Mexico. Percent growth by each month was January-3.5\%, February-6.5\%, March-5.9\%, April-9.1\%, May-20.3\%, June-12.6\%, July-9.6\%, August-4.9\%, September-1 1.4\%, October-6.3\%, November- $4.6 \%$, and December-5.3\%. Days rest were increased with decreasing growth rates for both grazing strategies.

Each pasture was 100 ha with moderate stocking rates of 1.25 ha/AUY. An animal unit was defined as an average dry matter daily consumption of $12 \mathrm{~kg}$. The model parameters for tick acquisition were set at 0.0003 for tick encounter, a conceptual representation of the proportion of tick locations in a given pasture encountered by the cattle and the pickup rate, proportion of encountered larvae that successfully attach to the host was set at 0.5 . To evaluate the effects of season, infested cattle were introduced into the model of each "clean" system in the spring ( 1 March) and the fall (27 September). These dates correspond to periods of peak purchases of replacement heifers and cows in the South Texas region as well as introduction of stocker steers. On

Table 1. Targeted graze:rest periods used for extensive (26-34 days:182-238 days graze:rest) and intensive (5-10 days: 35-70 days graze:rest), 8-pasture:1-herd short duration grazing (SDG) systems used in modeling pasture infestation patterns by cattle fever ticks in a mixed brush shrubland.

\begin{tabular}{lcccc}
\hline \hline \multirow{2}{*}{$\begin{array}{l}\text { Starting } \\
\text { Month }\end{array}$} & \multicolumn{2}{c}{ Extensive SDG } & & \multicolumn{2}{c}{ Intensive SDG } \\
\cline { 2 - 3 } \cline { 5 - 6 } & Gr aze & Rest & Graze & Rest \\
\hline January & 33 & 231 & 10 & 70 \\
February & 34 & 238 & 10 & 70 \\
March & 34 & 238 & 5 & 35 \\
April & 26 & 182 & $5 / 6$ & $35 / 42$ \\
May & 27 & 189 & 6 & 42 \\
June & 28 & 196 & 6 & 42 \\
July & 29 & 203 & $7 / 8$ & $49 / 56$ \\
August & 29 & 203 & 8 & 56 \\
September & 30 & 210 & $7 / 6$ & $49 / 42$ \\
October & 29 & 203 & $6 / 7$ & $42 / 49$ \\
November & 32 & 224 & 7 & 49 \\
December & 33 & 231 & 9 & 63 \\
\hline
\end{tabular}

Calendar months are relative to the start date of the grazing cycle and are not always directly equivalent to days grazed. Rotation cycle is based on forage production and not month of year.
Table 2. Duration of tick infestations in the system (ticks in the pastures and/or cow herd) and number of cattle reinfestations (acquisition of new larvae upon entering a sequential pasture) in an extensive (26-34 days: 182-238 days graze:rest) and intensive (5-10 days: 35-70 days graze:rest), 8-pasture:1-herd short duration graxing (SDG) system as a result of infested cattle entering the grazing cycle on 1 March (spring) or 27 September (fall) in a mixed brush shrubland.

\begin{tabular}{lcc}
\hline Grazing system & Duration of the infestation & $\begin{array}{c}\text { Number of cattle } \\
\text { reinfestations }\end{array}$ \\
\hline Intensive SDG & $>2$ years & 81 \\
Extensive SDG & 640 days & 4 \\
& $\ldots \ldots$ - Fall infestation- & 76 \\
Intensive SDG & $>2$ years & 2 \\
Extensive SDG & 425 days & \\
\hline
\end{tabular}

the day of introduction, cattle were infested with ticks partitioned across developmental stages of the 19-day, on-host period to provide a first day drop of 47.5 engorged females. Due to the stratified population of feeding ticks on these infested animals, engorged females would drop for approximately 30 days. The following attributes were recorded for each simulation: distribution of ticks among pastures resulting from the first and subsequent grazing cycles, and duration of infestations by pasturc within each system. Simulations were run assuming that no variation occurred among the pastures that would bias within-pasture tick distribution and survival, (eg. topography, soil type, uniform forage availability) and that there was no change in animal census. These assumptions enabled a more direct assessment of the grazing systems as influenced by variable cycle sequence and rest period. Acaricide applications were not implemented at any point in the simulation.

\section{Results}

At the system level, the intensive short duration grazing (SDG) system was infested for the full 2-year simulation for both the spring and fall introductions. Cattle became reinfested in the system 81 and 76 times over the 24-month simulation for the spring and fall introduction, respectively (Table 2). As expected, the longer rest sequence of the extensive SDG system resulted in fewer cattle reinfestations; 4 reinfestations for the spring initiated infestation lasting 640 days and 2 reinfestations for the fall initiated infestation lasting 425 days. These data indicated that at the system level varying graze:rest sequences did not prevent reinfestations, but did reduce the number of cattle reinfestations and the overall duration of the system infestation compared to the short rest periods associated with the intensive SDG.

Analysis of the 8 pastures in each system and date of introduction (Table 3), indicated that all pastures would become infested on the original graze cycle and continually be reinfested throughout the 24 month simulation for the intensive SDG. The fall introduction of infested cattle resulted in fewer reinfestations for the intensive SDG system than the spring introduction.

Graphic summaries of the simulations provided a more detailed examination of tick-cow-pasture interactions in intensive and extensive SDGs with different initial infestation dates. In the fallinitiated simulation of the extensive SDG (Fig. 2), ticks were distributed across the first 2 pastures in the first grazing cycle. 
Table 3. Number of times each pasture becomes reinfested by new engorged females in a 2-year simulation of an extensive (26-34 days: 182-238 days graze:rest) and intensive (5-10 days: 35-70 days graze:rest), 8-pasture:1-herd short duration grazing (SDG) system when infested cattle are introduced 1 March (spring) or 27 September (fall). An asterisk $\left({ }^{*}\right)$ indicates distribution of ticks in pastures following initial grazing cycle.

\begin{tabular}{|c|c|c|c|c|c|c|c|c|}
\hline \multirow[b]{2}{*}{ Grazing system } & \multicolumn{8}{|c|}{ Pasture } \\
\hline & 1 & 2 & 3 & 4 & 5 & 6 & 7 & 8 \\
\hline & \multicolumn{8}{|c|}{$\ldots \ldots \ldots$ Spring infestation- $\ldots \ldots$} \\
\hline Intensive SDG & $11^{*}$ & 9* & 9* & $10^{*}$ & $10^{*}$ & $10^{*}$ & $10^{*}$ & $10^{*}$ \\
\hline \multirow[t]{2}{*}{ Extensive SDG } & $2 *$ & $2^{*}$ & 2 & 1 & - & - & - & - \\
\hline & \multicolumn{8}{|c|}{-Fall infestation - } \\
\hline Intensive SDG & 8* & $7 *$ & $8^{*}$ & $6^{*}$ & $8 *$ & $9^{*}$ & $9^{*}$ & 8 \\
\hline Extensive SDG & $1 *$ & $1 *$ & - & - & - & - & - & - \\
\hline
\end{tabular}

Larvae surviving to infest cattle on the second graze cycle were sufficient in number (population data not shown) to produce additional engorged females to reinfest these same pastures, but insufficient to extend the distribution to other pastures. Aging larvae in infested pastures died out before cattle returned for the 3rd cycle. The first 2 pastures also became infested in the spring-initiated simulation of the extensive SDG (Fig. 3). Cattle reinfested on the 2nd cycle, reinfested the same pastures and distributed ticks into the 3rd pasture, however ticks in the 3rd pasture were unable to produce viable progeny due to winter induced delays in oviposition and incubation, and associated mortality (Teel et al. 1996). After the cattle passed through the first 2 pastures, the larvae remaining from the original graze cycle died out (cross-hatched blocks), however these pastures were also reinfested with gravid female ticks which produced eggs for the second generation of larvae that did not emerge until the following spring. Larvae from this second generation infested cattle on their $3^{\text {rd }}$ rotation and were in sufficient number to enable cattle to distribute ticks to 2 additional pastures. Late fall-early winter larval die-out in the second year terminated the infestation across the system.

The more rapid dynamics of the intensive SDG simulation produced substantially different spatial and temporal results. In the fall-initiated simulation (Fig. 4), 7 of 8 pastures were infested on the first graze cycle. Winter-delayed tick development, resulting from prolonged oviposition and egg incubation due to low temperature, prevented cattle reinfestation until the $3^{\text {rd }}$ graze cycle, when ticks picked up in pastures $1-5$ enabled distribution of ticks to all pastures. This $3^{\text {rd }}$ graze cycle coincided with the shortest

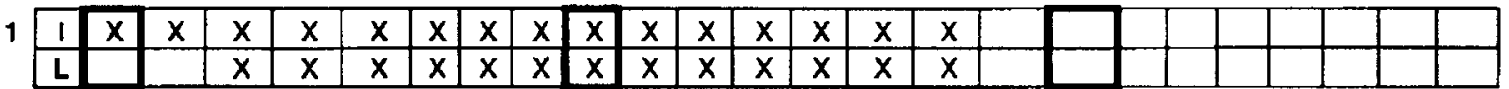

\begin{tabular}{|l|l|l|l|l|l|l|l|l|l|l|l|l|l|l|l|l|l|l|l|l|l|l|l|l|}
\hline $\mathbf{I}$ & & $\mathrm{x}$ & $\mathrm{x}$ & $\mathrm{x}$ & $\mathrm{x}$ & $\mathrm{x}$ & $\mathrm{x}$ & $\mathrm{x}$ & $\mathrm{x}$ & $\mathrm{x}$ & $\mathrm{x}$ & $\mathrm{x}$ & $\mathrm{x}$ & $\mathrm{x}$ & $\mathrm{x}$ & & & & & & & & & \\
\hline $\mathrm{L}$ & & & & $\mathrm{x}$ & $\mathrm{x}$ & $\mathrm{x}$ & $\mathrm{x}$ & $\mathrm{x}$ & $\mathrm{x}$ & $\mathrm{x}$ & $\mathrm{x}$ & $\mathrm{x}$ & $\mathrm{x}$ & $\mathrm{x}$ & $\mathrm{x}$ & & & & & & & & & \\
\hline
\end{tabular}
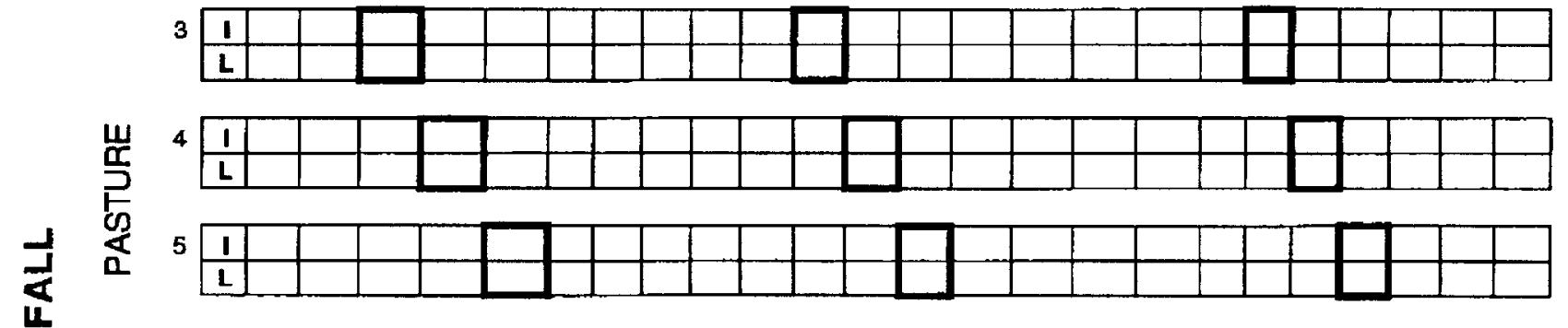

\begin{tabular}{|l|l|l|l|l|l|l|l|l|l|l|l|l|l|l|l|l|l|l|l|l|l|l|l|}
\hline $\mathbf{I}$ & & & & & & & & & & & & & & & & & & & & & & & \\
\hline $\mathrm{L}$ & & & & & & & & & & & & & & & & & & & & & & \\
\hline
\end{tabular}
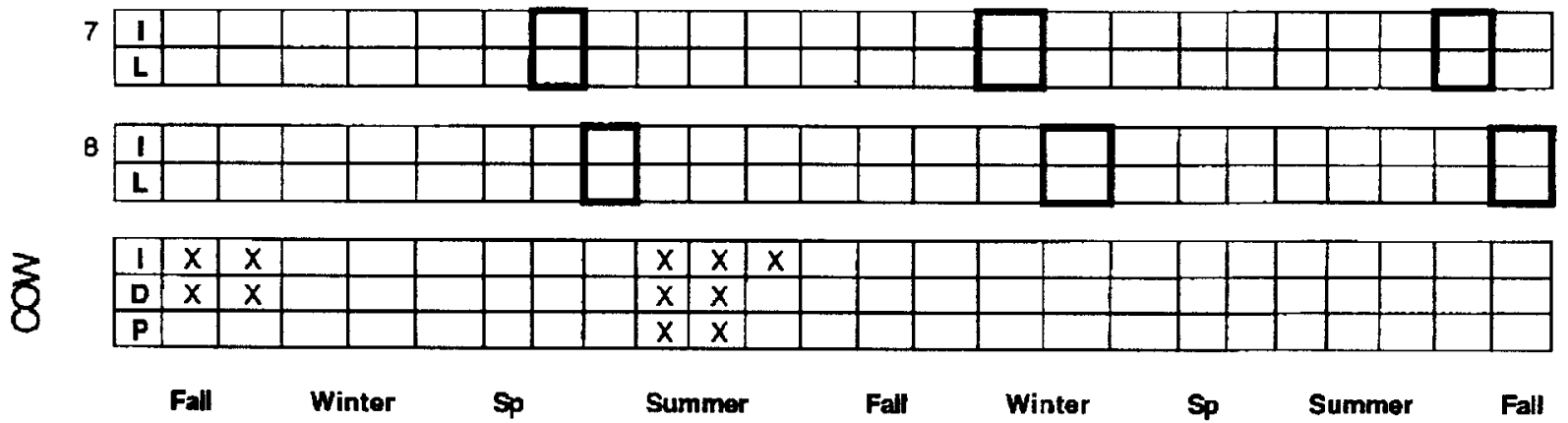

Fig. 2. Summary of cattle fever tick distribution and survival resulting from a 2-year simulation of an 8-pasture, 1-herd short duration grazing system in a mixed-brush scrubland with an extensive graze:rest (27-34 days:182-238 days) schedule initiated by introducing infested cattle in the fall (27 September). The width of boxes in a vertical column are adjusted to indicate the relative duration of days grazed in the system. Pasture boxes outlined in bold indicate intervals of grazing in a given pasture and their sequence shows the grazing cycle across the 8 pastures. The status of each pasture is indicated by an "X" as infested (I) from the time engorged ticks first drop until all larvae are dead. The presence of larvae $(L)$ following emergence from eggs also is indicated by an " $X$ ". The status of the average cow in the herd is indicated using " $X$ " in the lower horizontal bars to define whether the animals are infested (I), dropping engorged female ticks back into the pasture (D), or picking up larvae (P). 


\begin{tabular}{|c|c|c|c|c|c|c|c|c|c|c|c|c|c|c|c|c|c|c|c|c|c|c|c|c|}
\hline & $\mathrm{x}$ & $\mathrm{x}$ & $\mathrm{x}$ & $\mathrm{x}$ & $\mathrm{x}$ & $\mathrm{x}$ & $\mathrm{x}$ & $\mathrm{x}$ & $\mathrm{x}$ & $\mathrm{x}$ & $\mathrm{x}$ & $\mathrm{x}$ & $\mathrm{x}$ & $\mathrm{x}$ & $\mathrm{x}$ & $\mathrm{x}$ & $\mathrm{x}$ & $\mathrm{x}$ & $\mathrm{x}$ & $\mathrm{x}$ & $\mathrm{x}$ & $\mathrm{x}$ & & \\
\hline $\mathrm{L}$ & & $\mathrm{x}$ & $\mathrm{x}$ & $\mathrm{x}$ & $\mathrm{x}$ & $\mathrm{x}$ & $\mathrm{x}$ & $\mathrm{x}$ & $\mathrm{x}$ & $\mathrm{x}$ & $\mathbf{W}$ & & &
\end{tabular}

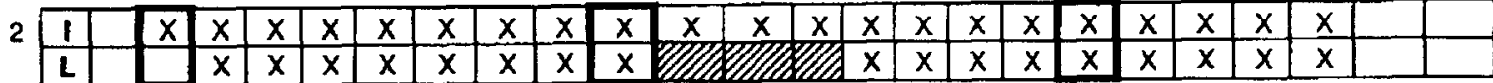

3
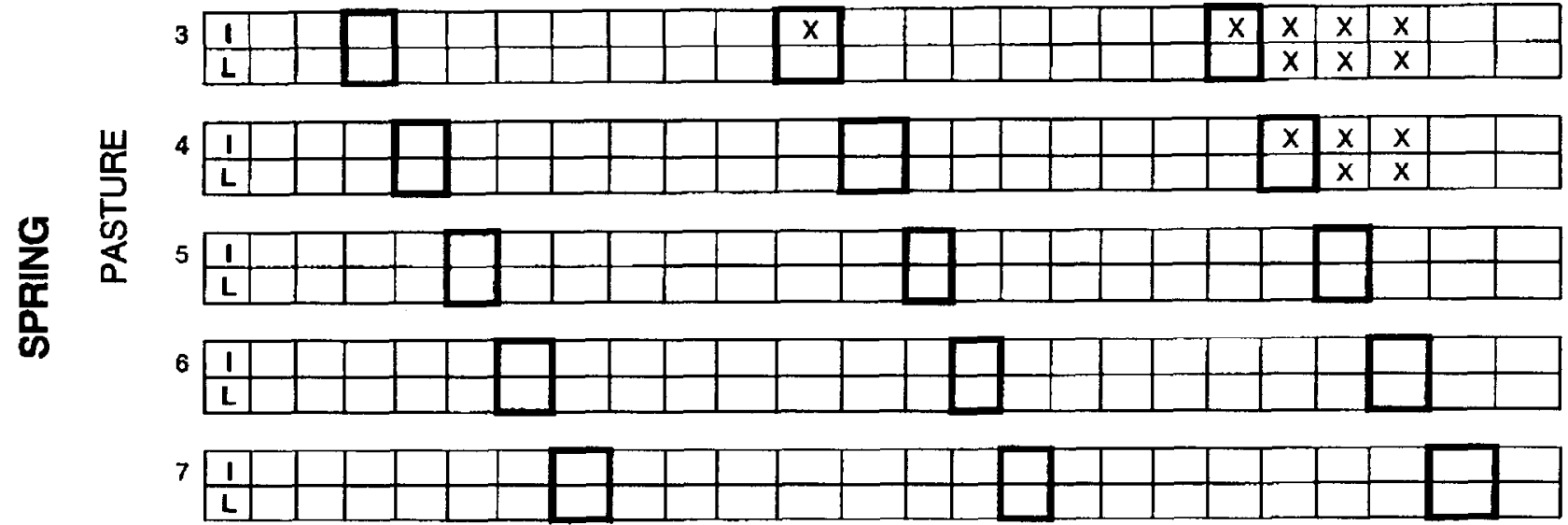

8

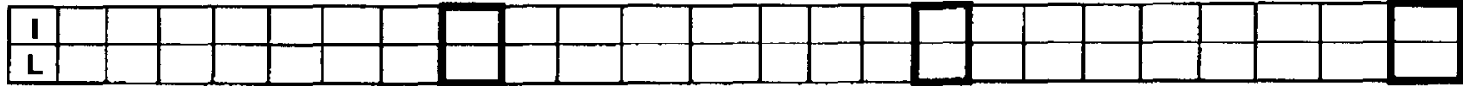

8

\begin{tabular}{|l|l|l|l|l|l|l|l|l|l|l|l|l|l|l|l|l|l|l|l|l|l|l|l|l|}
\hline $\mathbf{I}$ & $\mathrm{x}$ & $\mathrm{x}$ & & & & & & & $\mathrm{x}$ & $\mathrm{x}$ & $\mathrm{x}$ & & & & & & $\mathrm{x}$ & $\mathrm{x}$ & $\mathrm{x}$ & $\mathrm{x}$ & & & & \\
\hline $\mathbf{D}$ & $\mathrm{x}$ & $\mathrm{x}$ & & & & & & & $\mathrm{x}$ & $\mathrm{x}$ & $\mathrm{x}$ & & & & & & $\mathrm{x}$ & $\mathrm{x}$ & $\mathrm{x}$ & $\mathrm{x}$ & & & & \\
\hline $\mathbf{P}$ & & & & & & & & & $\mathrm{x}$ & $\mathrm{x}$ & & & & & & & $\mathrm{x}$ & $\mathrm{x}$ & & & & & & \\
\hline
\end{tabular}

Sp Summer Fall Winter Spring Summer Fall Winter

Fig. 3. Summary of cattle fever tick distribution and survival resulting from a 2-year simulation of an 8-pasture, 1-herd short duration grazing system in a mixed-brush scrubland with an extensive graze:rest (27-34 days:182-238 days) schedule initiated by introducing infested cattle in the spring (1 March). The width of boxes in a vertical column are adjusted to indicate the relative duration of days grazed in the system. Pasture boxes outlined in bold indicate intervals of grazing in a given pasture and their sequence shows the grazing cycle across the 8 pastures. The status of each pasture is indicated by an " $X$ " as infested (I) from the time engorged ticks first drop until all larvae are dead. The presence of larvae $(L)$ following emergence from eggs also is indicated by an " $X$ ". The status of the average cow in the herd is indicated using an " $X$ " in the lower horizontal bars to define whether the animals are infested (I), dropping engorged female ticks back into the pasture (D), or picking up larvae (P).

days grazed. Pastures and cattle remained continuously infested until the following winter when winter larval mortality interrupted cattle infestations through periods of varying duration. The reappearance of larvae was produced from engorged ticks dropped during the previous 2 graze cycles. These were sufficient to reinfest the entire system.

In contrast to fall, the spring-initiated simulation (Fig. 5) resulted in all 8 pastures becoming infested during the first graze cycle and cattle becoming reinfested at the beginning of the second graze cycle. The rapid infestation of the system was aided by the influence of warmer spring conditions coincident with the shortest grazing days. Early winter larval mortality temporarily freed cattle of tick infestation during the $6^{\text {th }}$ to $7^{\text {th }}$ graze cycles. New larvae were subsequently produced from engorged ticks dropped in the $5^{\text {th }}$ and $6^{\text {th }}$ graze cycles. The return of spring and short graze days brought about a reinfestation of the entire system. The pattern of discontinuous larval presence appeared again in year 2, but was out of phase to that in year 1. This pattern, which was similar to that in the fall simulation, was produced by larval mortality in the simulation model for this habitat type.
The present simulation model holds 2 dynamic variables to a constantly repeating pattern: forage production and tick development and survivorship in the field. Holding these variables to a constant pattern enables evaluation of the simulation results to be focused on grazing cycle and initiation of infestation. Both forage production and tick development and survivorship are affected by temperature, relative humidity, and rainfall. Weather-related changes in grazing days and tick populations would produce different simulation results. Likewise, different habitat types and starting dates are also known to produce different results in consistently meaningful directions (Teel et al. 1996, 1997). Weather driven variation in this model will be a focus of future work.

\section{Discussion}

When contrasting these results to simulations conducted on a similar set of environmental conditions in south Texas (Teel et al. $1996,1997)$, it becomes readily apparent that flexible rotations 


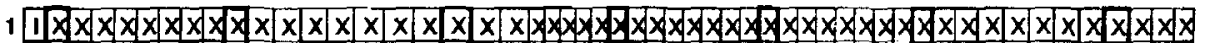

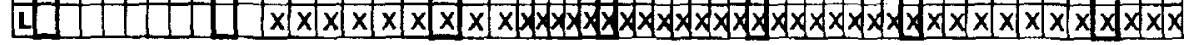

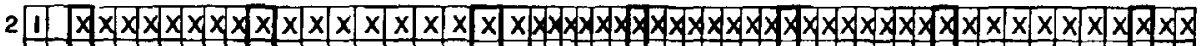
LLI I I

3 1

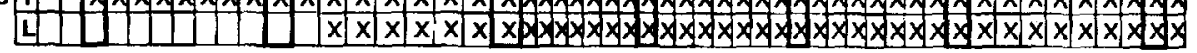

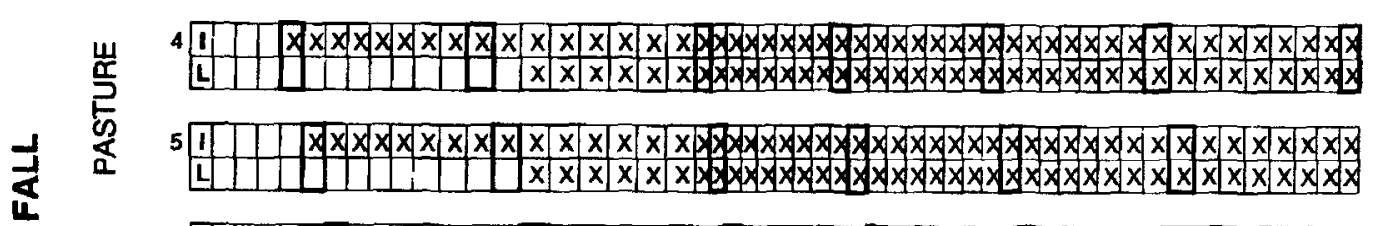

6 T LIIIIIII

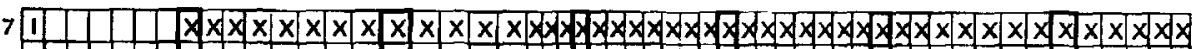
LUDU1

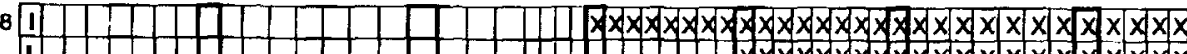
LIIDHDI

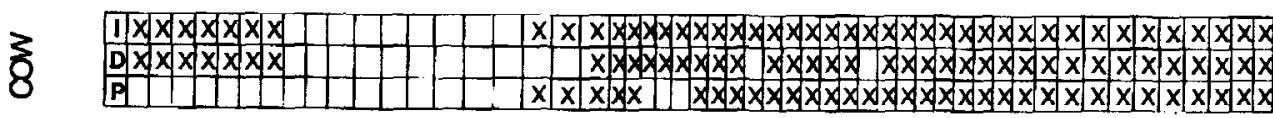

Fal

Winter

Spring

Surmmer

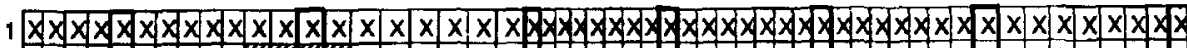
$\times \times \times \times \times \times \times \times \times \times$
0

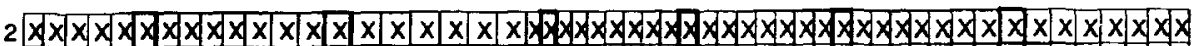

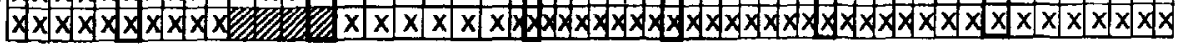

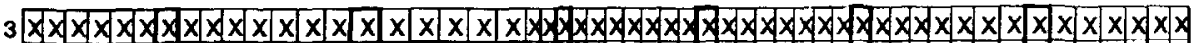

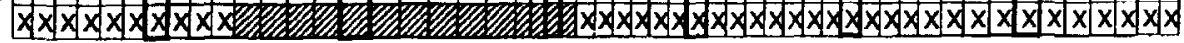

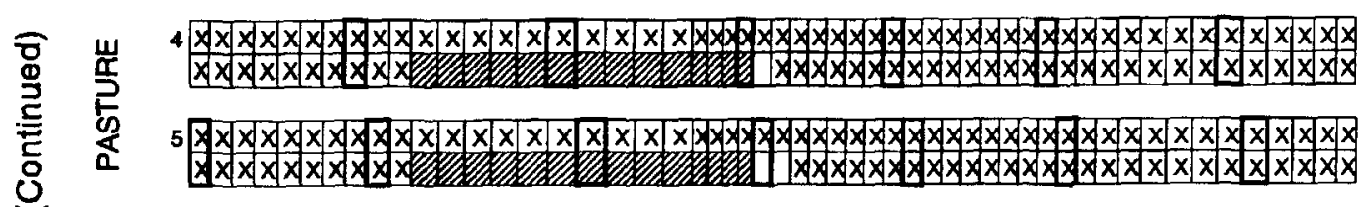

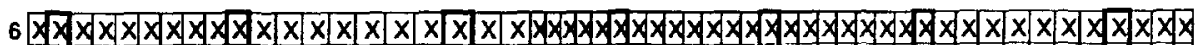

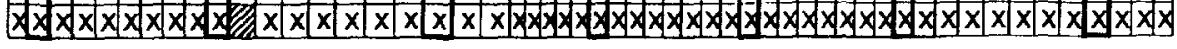

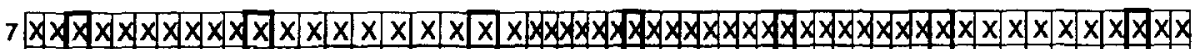

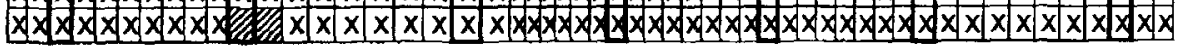

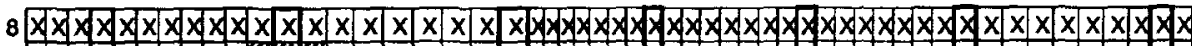

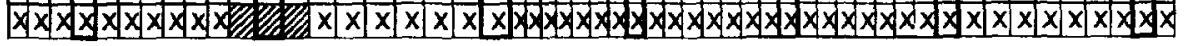

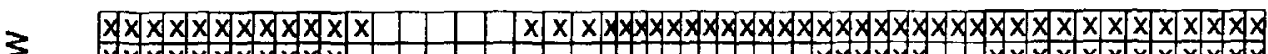

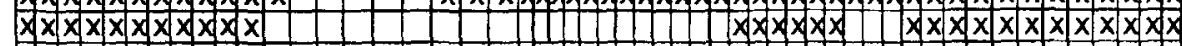

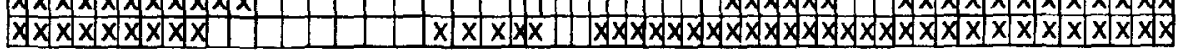

Winter

Spiting

Summer

Fig. 4. Summary of cattle fever tick distribution and survival resulting from a 2-year simulation of an 8-pasture, 1-herd short duration grazing system in a mixed-brush scrubland with an intensive graze:rest (5-10 days:35-70 days) schedule initiated by introducing infested cattle in the fall (27 September). The width of boxes in a vertical column are adjusted to indicate the relative duration of days grazed in the system. Pasture boxes outlined in bold indicate intervals of grazing in a given pasture and their sequence shows the grazing cycle across the 8 pastures. The status of each pasture is indicated by an "X" as infested (I) from the time engorged ticks first drop until all larvae are dead. The presence of larvae $(L)$ following emergence from eggs also is indicated by an " $X$ ". The status of the average cow in the herd is indicated in the lower horizontal bars to define whether the animals are infested (I), dropping engorged female ticks back into the pasture (D), or picking up larvae (P). 
1 1.

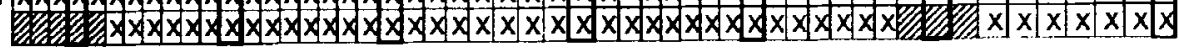

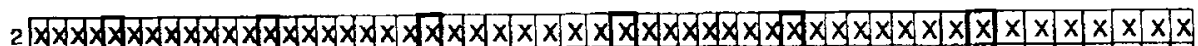

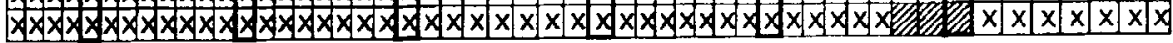

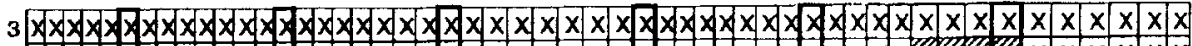

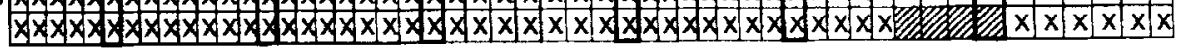

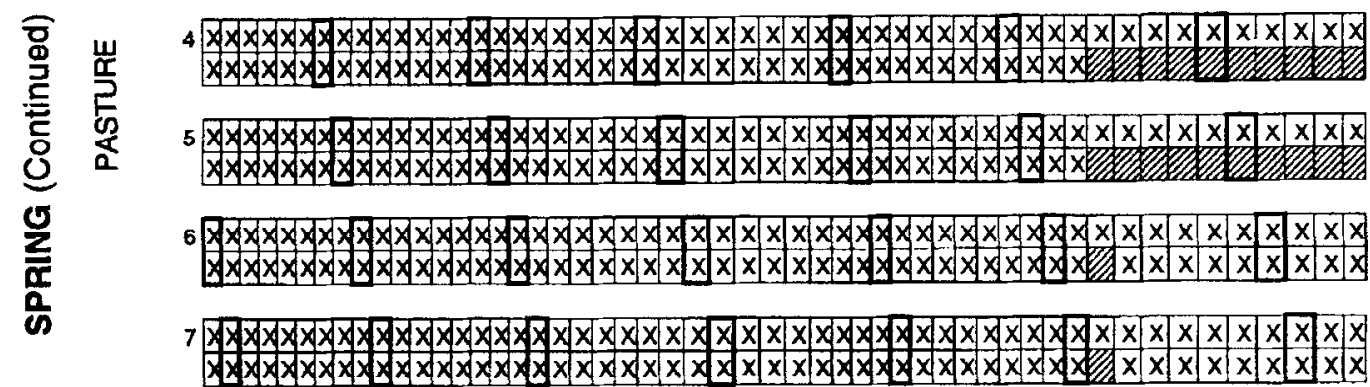

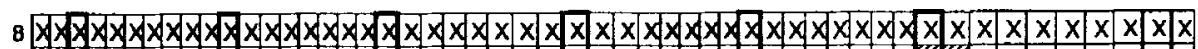

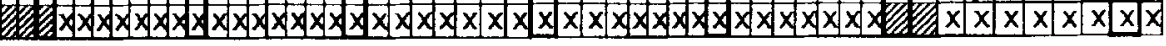

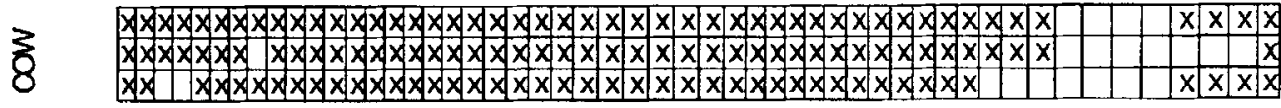

Spring Summer Fall Winter

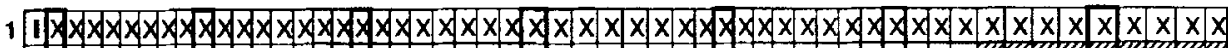

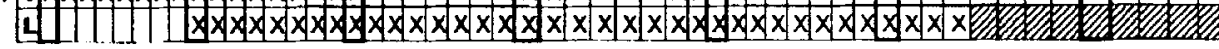

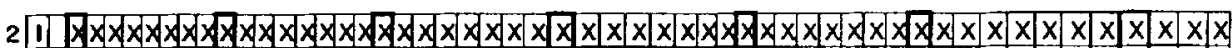

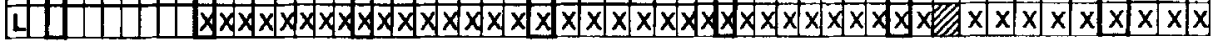

3 [

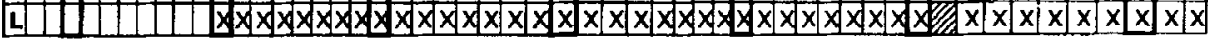

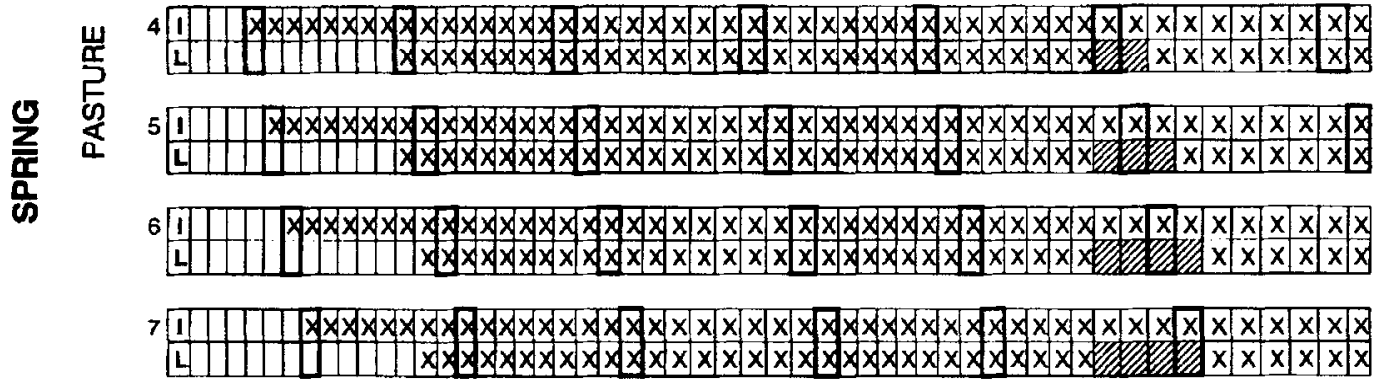

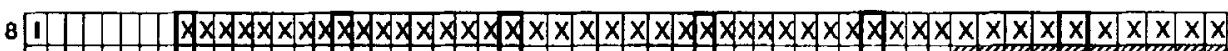

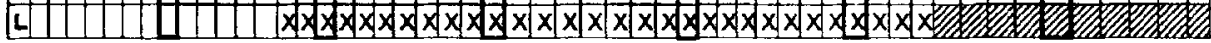

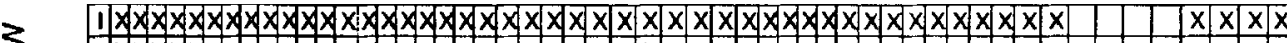
8 - 8 (1)

Spring

Summer

Fall

Winter

Fig. 5. Summary of cattle fever tick distribution and survival resulting from a 2-year simulation of an 8-pasture, 1-herd short duration grazing system in a mixed-brush scrubland with an intensive graze:rest (5-10 days:35-70 days) schedule initiated by introducing infested cattle in the spring (1 March). The width of boxes in a vertical column are adjusted to indicate the relative duration of days grazed in the system. Pasture boxes outlined in bold indicate intervals of grazing in a given pasture and their sequence shows the grazing cycle across the 8 pastures. The status of each pasture is indicated by an " $X$ " as infested (I) from the time engorged ticks first drop until all larvae are dead. The presence of larvae (L) following emergence from eggs also is indicated by an " $X$ ". The status of the average cow in the herd is indicated using " $X$ " in the lower horizontal shaded bars to define whether the animals are infested (I), dropping engorged female ticks back into the pasture (D), or picking up larvae (P). 
following forage growth/quality cycles will not overcome the reinfestation pressures noted with rest periods shorter than the 147 days previously simulated for the mixed brush shrublands. Longer periods of days grazed as exhibited in the extensive short duration grazing (SDG) reduces the number of pastures originally infested and longer periods of days rest reduce the chances for larvae to survive when the intervals are 180-240 days in duration. The season of introduction of infested cattle in both the intensive and extensive systems affected the dynamics of tick dispersal and survival among pastures as well as occurrence of tick-free periods on the cattle. The dynamics of the system affect opportunities for detection of the infestation and potential intervention strategies with intensive SDG systems using variable rotation strategies (Palmer et al. 1976, Sutherst et al. 1979). Spring introductions would be more problematic for managers of intensive SDG than fall introductions, given the low frequency and duration of tickfree periods associated with spring introductions. Applications of an acaricide would likely be required more frequently in the intensive SDG versus the extensive SDG systems. This would depend, however, upon whether eradication or control was the goal.

Although the extensive SDG system with 180- to 240-day rest periods was much more resistant to reinfestation from both a spring and fall introduction, other management issues arise that affect the immunology of the animal via nutritional status. Research has indicated that use of extensive SDG systems with long rest periods results in poorer nutritional status of the animal as reflected in conception rates and calf weaning weights (Heitschmidt and Taylor 1991). Therefore, special emphasis would have to be made on setting stocking rates to avoid nutritional stress and establish nutritional monitoring programs to offset nutritional deficiencies arising from application of these types of systems. Recent breakthroughs in fecal monitoring systems via near-infrared reflectance spectroscopy (Lyons and Stuth 1992) allow producers to monitor the nutritional status of free-ranging cattle and provide least-cost supplementation to mediate nutritional deficiencies. This nutritional monitoring technology could allow ranchers to reconsider these types of systems whether their goal was to reduce risk of disease introduction via the cattle fever tick, or to maintain the enzootic stability of disease by balancing a maintenance level of ticks to provide a sufficient inoculation rate to sustain natural immunity to the disease while containing economic losses (Haile et al. 1992, Friedhoff and Smith 1981). Additional factors such as cattle breed, level of tick-host resistance, and cattle density, are important considerations in these assessments and are under evaluation in other simulation studies.

The model presented in this paper offers the regulatory agencies and ranching industry a viable tool to assess risk of tick spread on infested ranches and provides a mechanism to design optimal intervention strategies. The open blocks for cow status in Figures 2-5 indicate that the probability of detecting ticks in any pasture of the system is quite variable. Prediction of likelihoods of pasture infestation would allow inspectors to improve pasture inspection and tick detection. Longer rest, extensive SDG systems offer ranchers a reduced risk option for tick reinfestation where cattle are the only host involved. Our analyses indicate that season of introduction plays a much greater role in infestation patterns than rotational decision making if the rest periods are less than approximately 150 days.

We believe the simulation results for the variable rotational grazing systems are reasonably representative of tick-cattle-landscape interactions based upon comparisons of tick life histories during rest periods in each pasture and to the influences of season, habitat, and season of initial infestation previously described (Teel et al. 1996, 1997). Field validation of these simulations cannot be conducted in the U.S. due to constraints of quarantine and eradication; however, field validation studies are underway in Northeastern Mexico and opportunities exist for similar studies to be conducted in Venezuela.

\section{Literature Cited}

Barnard, D.R.1991. Mechanisms of host-tick contact with special reference to Amblyomma americanum (Acari: Ixodidae) in beef cattle forage areas. J. Med. Entomol. 28:557-564.

Fragoso, H., N.S. Soberanes, M. Ortiz, M. Vargas, and A. Ortiz. 1995. Epidemiology of acaricide resistance in the Boophilus microplus tick in Mexico. pp 45-57. Proc. III Int'1. Symposium on Animal Parasites. October 11-13, 1995, Acapulco, Mexico.

Friedhoff, K.T. and R.D. Smith. 1981. Transmission of Babesia by ticks. pp 267-321. In: M.Ristic and J.P Kreier (eds). Babesiosis. Academic Press, N.Y.

Haile, D.G., G.A. Mount, and L.M. Cooksey. 1992. Computer simulation of Babesia bovis (Babes) and B. bigemina (Smith \& Kilborne) transmission by Boophilus cattle ticks (Acari: Ixodidae). J. Med. Entomol. 29:246-258.

Heitschmidt, R.K. and C.A. Taylor, Jr. 1991. Livestock production. pp. 161-177. In: R.K. Heitschmidt and J.W. Stuth (eds). Grazing Management: An Ecological Perspective. Timber Press, Portland, Ore.

Lyons, R.K. and J.W. Stuth. 1992. Fecal NIRS equations predict diet quality of free-ranging cattle. J. Range Manage. 45:614-618.

McCosker, P.J. 1981. The global importance of babesiosis. pp. 1-24 In: M.Ristic and J.P Kreier (eds). Babesiosis. Academic Press, N.Y.

Palmer, W. A., N. L. Treverrow, and G. H. O'Neill. 1976. Factors affecting the detection of infestations of Boophilus microplus in tick control programs.Australian Vet. J. 52:321-324.

Schmidtmann, E.T. 1994. Ecologically based strategies for controlling ticks. pp 240-280 In: D.E. Sonenshine and T.N. Mather (eds). Ecological dynamics of tick-borne zoonoses. Oxford Univ. Press, N.Y.

Sonenshine, D.E. 1993. Tick-borne protozoal diseases. pp. 107-156. In: Biology of Ticks, Vol. II. Oxford Univ. Press, N.Y.

Sutherst, R. W., G. A. Norton, N.D. Barlow, G.R. Conway, M. Birley, and H. N.Comins. 1979. An analysis of management strategies for cattle tick (Boophilus microplus) control in Australia. J. Appl. Ecol. 16:359-382.

Sutherest, R. W., R. B. Floyd, A. S. Bourne, and M. J. Dallwitz. 1986. Cattle grazing behavior regulates tick populations. Experientia 42: 194-196.

Tatchell, R. J. 1992. Ecology in relation to integrated tick management. Insect. Sci. Applic. 13:551-561.

Teel, P. D. 1991. Application of modelling to the ccology of Boophilus annulatus (Say) (Acari: Ixodidae). J. Agr. Entomol. 8:291-296.

Teel, P.D., S.L. Marin, and W.E. Grant. 1996. Simulation of host-parasite-landscape interactions: Influence of season and habitat on cattle fever tick (Boophilus sp.) population dynamics. Ecol. Modelling 84:19-30.

Teel, P.D., S.L. Marin, W.E. Grant, and J. W. Stuth. 1997. Simulation of host-parasite-landscape interactions: Influence of season and habitat on cattle fever tick (Boophilus sp.) population dynamics in rotational grazing systems. Ecol. Modelling 97:87-97.

Waters, K. S. 1972. Grazier's finding on pasture spelling for tick control. Queensland Agr.. J., April 1992. Australia.

Wharton, R.H., K.L.S. Harley, P.R. Wilkinson, K.B. Utech, and B.M. Kelley. 1969. A comparison of cattle tick control by pasture spelling, planned dipping, and tick-resistant cattle. Aust. J. Agr. Res. 20:783-797. 